\title{
Survival following initiation of non-invasive ventilation during hospitalization for chronic hypercapnic respiratory failure
}

\author{
Benjamin Daines* BS, Nitish Mittal* BS, Amr Ismail MD, Gilbert Berdine MD
}

\begin{abstract}
Patients hospitalized with chronic hypercapnic respiratory failure often have comorbidities and are at increased risk for mortality after discharge. Non-invasive ventilation (NIV) has become a common therapy for these patients to improve gas exchange both while hospitalized and after discharge. To understand the survival of hypercapnic respiratory failure patients started on home NIV therapy, a prospective study was conducted analyzing rate of survival and predictors of mortality. Patients had a significant one-year mortality rate of $16.7 \% \pm 0.71 \%$. Analysis of demographic and physiologic data revealed that the only significant predictor of mortality was hours of NIV use per day, with greater use associated with increased mortality. Although initial results indicate that NIV can be an effective long term therapy for chronic hypercapnic respiratory failure, these patients remain at high risk of mortality and require regular monitoring. Continued study will increase this cohort and follow it for longer periods of time to better understand the predictors of mortality in patients hospitalized with chronic hypercapnic respiratory failure.
\end{abstract}

Keywords: Obesity hypoventilation syndrome, noninvasive ventilation, hypercapnic respiratory failure

\section{INTRODUCTION}

Hypercapnia is associated with several disease processes, including obesity-hypoventilation syndrome $(\mathrm{OHS})$, obstructive sleep apnea (OSA), and chronic obstructive pulmonary disease (COPD). The presence of persistent hypercapnia could be related to increased mortality and rehospitalization, and this association has been seen in COPD patients with persistent hypercapnia. ${ }^{1,2}$ Improving gas exchange using home noninvasive ventilation (NIV) would be expected to reduce mortality and morbidity in patients with chronic hypercapnia. However, clinical trials have failed to show this improvement in outcome.

Corresponding author: Gilbert Berdine Contact Information: Gilbert.Berdine@ttuhsc.edu DOI: 10.12746/swrccc.v9i37.793
Non-invasive ventilation includes continuous positive airway pressure (CPAP), bilevel positive airway pressure (BiPAP), and average volume assured pressure support ventilation (AVAPS). Patients requiring NIV due to inadequate gas exchange usually have a severe disease process and are at an increased risk for mortality and morbidity. Our study aimed to monitor these patients closely (once monthly) to gather data about compliance, common issues with NIV machines, and several other outcomes. It also offered the patients an opportunity to be seen in clinic to manage their acute issues.

\section{METHODS}

\section{ObJective}

The goal of this study was to evaluate the survival of patients hospitalized with chronic hypercapnic

\footnotetext{
${ }^{*}$ Benjamin Daines and Nitish Mittal are co-first authors.
} 
respiratory failure, begun on NIV in the hospital, and discharged from the hospital with orders for home NIV.

\section{STUDY MANAGEMENT}

This is a prospective study. Patients were recruited by the pulmonary consult service at the time that NIV was begun in the hospital. Entry into the study was documented by a progress note recording name, medical record number, date of birth, gender, age at the time of entry into the study, telephone number to contact the patient after discharge, date that NIV was initiated, and arterial $\mathrm{pCO}_{2}$ prior to the initiation of NIV. Insurance provider and durable medical equipment (DME) supplier were included if available to assist with follow-up. At the time of discharge from the hospital, current NIV mode and settings, hours of NIV use each day, arterial $\mathrm{pCO}_{2}$, and venous total $\mathrm{CO}_{2}$ were added to the initial data note.

The data base included the most recent follow-up date and patient status. Patients have been enrolled since October 1, 2018. A total of 26 patients were enrolled prior to September 1, 2019. Five patients requested removal from the study; the data for these patients were not included in analysis. Of the remaining 21 patients, 5 patients have died; survivals for these patients were calculated as date of death minus date of entry. An attempt was made to contact live patients remaining in the study each month. If a patient had an encounter recorded in the electronic medical record (EMR), the date of follow-up was updated to the date of this encounter. An attempt was made to contact the remaining patients for follow-up by telephone. These telephone encounters were recorded in EMR with date of encounter, hours of use, and any problems with NIV. Patients with problems were offered an opportunity to see a pulmonary physician to assist with problems. No billing for these telephone encounters was generated.

\section{Statistical Analysis}

Statistical analysis was performed using IBM SPSS Statistics. Results were summarized using means and standard deviations, medians, and number with percentages. Survival was calculated using
Table 1. Demographics

\begin{tabular}{|l|l|c|}
\hline Age & Years, mean \pm SD & $58.4 \pm 9.5$ \\
\hline Gender & Male, N (\%) & $13(61.9 \%)$ \\
\hline & Female, N (\%) & $8(38.1 \%)$ \\
\hline Ethnicity & White, N (\%) & $15(71.4 \%)$ \\
\hline & Hispanic, N (\%) & $4(19.0 \%)$ \\
\hline & Black, N (\%) & $2(9.5 \%)$ \\
\hline
\end{tabular}

Kaplan-Meier curve analysis, and predictors of mortality were analyzed using independent samples T-tests and Chi-square tests.

\section{Study Approval}

This study was approved (QIRB Approval \#19038) by Institutional Review Board at Texas Tech University Health Sciences Center, Lubbock, TX.

\section{RESULTS}

A total of 26 patients were enrolled into the study. Five patients requested removal from the study; the data for these patients were not included in the analysis. The initial patient population included the remaining 21 patients. Table 1 reports the mean age, sex, and race of the participants remaining in the study. Five patients were treated with BiPAP, 2 patients were treated with BiPAP-ST, and 14 patients were treated with AVAPS. Figure 1 reports the survival function of participants in the study, with living participants at each time point indicated by a censored data point. Table 2 indicates that the 90-day and 365-day mortality rates of chronic hypercapnic respiratory failure patients using NIV therapy in the study were $11.5 \% \pm 0.63 \%$ and $16.7 \% \pm 0.71 \%$, respectively. These data censor participants who requested removal from the study prior to 90 or 365 days.

Table 3 reports potential predictors of mortality for participants in the study including demographic information, home NIV settings, physiologic data collected at admission, and physiologic data collected at discharge. Tables 3 and 4 report only mortality data censoring participants who were lost to follow-up, as 


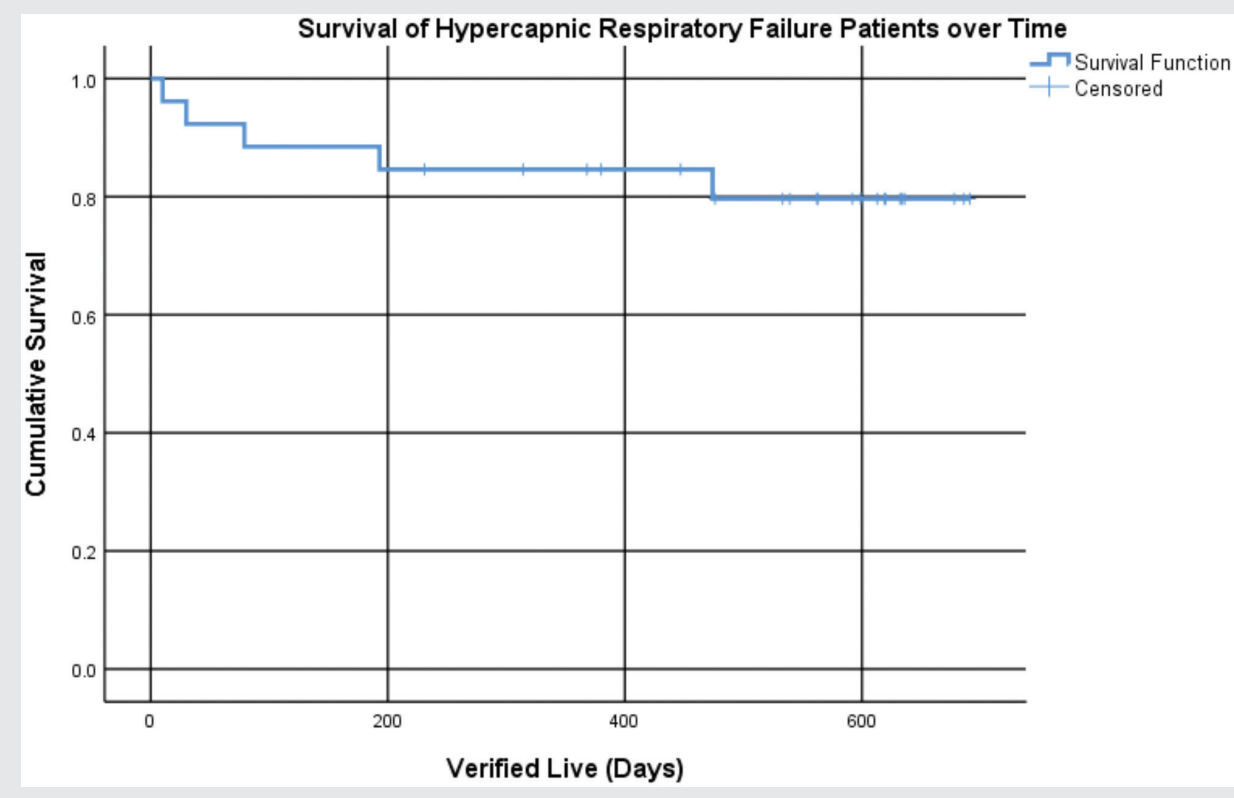

Figure 1. Kaplan-Meier Survival Curve.

their status is not known at this time. Neither arterial $\mathrm{pCO}_{2}$ at admission and discharge nor venous total $\mathrm{CO}_{2}$ at discharge was significantly different between participants who have died and those who are still alive. The only predictor of mortality from preliminary data appears to be hours of NIV use per day, which was significantly higher in participants who have died. Table 4 reports additional predictors of mortality using Chi-square tests demonstrating no significant correlation between mortality and race or sex in participants.

\section{Discussion}

This prospective study evaluates survival of patients hospitalized with chronic hypercapnic respiratory failure who were started NIV for the first time and who were discharged on home NIV. Non-invasive ventilation has been used in hospitalized patients as temporary therapy for acute respiratory failure to avoid endotracheal intubation and mechanical ventilation.

Table 2. Mortality Rate

\begin{tabular}{|l|l|}
\hline & $\%$ Deceased $\pm \%$ SD \\
\hline 90-Day Mortality Rate & $11.5 \% \pm 0.63 \%$ \\
\hline 365-Day Mortality Rate & $16.7 \% \pm 0.71 \%$ \\
\hline
\end{tabular}

The continuation of NIV following discharge from the hospital to treat chronic hypercapnic respiratory failure is a relatively new management strategy. Little is known about the long term outcomes in these

Table 3. Predictors of Mortality

\begin{tabular}{|l|c|c|c|}
\hline & $\begin{array}{c}\text { Deceased } \\
\text { Participants } \\
\text { (mean } \pm \text { SD) }\end{array}$ & $\begin{array}{c}\text { Living } \\
\text { Participants } \\
\text { (mean } \pm \text { SD) }\end{array}$ & P value \\
\hline Age, years & $65.8 \pm 4.1$ & $56.1 \pm 9.6$ & 0.256 \\
\hline $\begin{array}{l}\mathrm{pCO}_{2} \text { prior to } \\
\text { NIV therapy, } \\
\mathrm{mmHg}\end{array}$ & $65.0 \pm 16.0$ & $77.4 \pm 15.6$ & 0.883 \\
\hline $\begin{array}{l}\mathrm{pCO}_{2} \text { after } \\
\text { therapy at } \\
\text { discharge, } \\
\text { mmHg }\end{array}$ & $52.8 \pm 10.3$ & $58.3 \pm 8.9$ & 0.586 \\
\hline $\begin{array}{l}\text { Venous CO } \\
\text { after therapy } \\
\text { at discharge, } \\
\text { meq/L }\end{array}$ & $30.4 \pm 7.3$ & $34.0 \pm 3.4$ & 0.091 \\
\hline $\begin{array}{l}\text { NIV use } \\
\text { (hours/day) }\end{array}$ & $6.5 \pm 1.6$ & $5.1 \pm 3.6$ & $\mathbf{0 . 0 1 9}$ \\
\hline
\end{tabular}

Numbers in bold represent $\mathrm{p}$ values less than 0.05 . 
Table 4. Predictors of Mortality cont.

\begin{tabular}{|l|l|c|c|c|}
\hline & & $\begin{array}{c}\text { Deceased } \\
\text { Participants }\end{array}$ & $\begin{array}{c}\text { Living } \\
\text { Participants }\end{array}$ & P Value \\
\hline Gender & Male & 2 & 11 & 0.262 \\
\hline & Female & 3 & 5 & \\
\hline Ethnicity & White & 4 & 11 & 0.355 \\
\hline & Hispanic & 0 & 4 & \\
\hline & Black & 1 & 1 & \\
\hline
\end{tabular}

Pearson Chi-Square.

patients. Our study monitored these patients monthly following discharge from the hospital to accumulate data about survival.

The average age of the participants was $58.4 \pm 9.5$ with a gender ratio of 1.6:1 (M: F). Enrollment into the study began in October of 2018. Although enrollment and follow-up remain ongoing, we report on patients enrolled by September 1, 2019 to permit follow-up of at least one year. The 90-day and 365-day mortality rates of the patients enrolled were $11.5 \% \pm 0.63 \%$ and $16.7 \% \pm 0.71 \%$, respectively. Overall, there was a significant mortality, but the patients did better than expected prior to starting the study. A recent study in Medicare beneficiaries hospitalized with COPD exacerbation found the one-year mortality rate to be $26.2 \% .^{3}$ We anticipated a one-year mortality of at least $20 \%$ prior to beginning the study due to severity of disease, difficulties of compliance with therapy, and insurance difficulties in obtaining home NIV equipment. We will continue to monitor these patients to determine 2-year, 3-year, and 5-year mortality rates.

The only significant predictor of mortality appears to be hours of NIV use per day. It is not clear as to why deceased patients have significantly greater use of the equipment. A study conducted on chronic hypercapnic COPD patients found that one and twoyear survival rates in patients with NIV were $87.7 \%$ and $71.8 \%$, respectively, as compared to $56.7 \%$ and $42 \%$ in patients without NIV use. ${ }^{4}$ Patients with NIV were using the equipment for $6.4 \pm 2.6 \mathrm{~h} /$ day. Hence, this study emphasizes the importance of receiving NIV for a certain number of hours for the long-term survival and a decrease in mortality rate. Similarly, in our study, one possible explanation for the correlation between hours of NIV use and mortality could be the presence of more severe disease prior to therapy for patients who died, but the patients who died had less severe $\mathrm{CO}_{2}$ retention even though the difference in $\mathrm{CO}_{2}$ retention did not reach statistical significance. The $\mathrm{pCO}_{2}$ at admission, the $\mathrm{pCO}_{2}$ at discharge, and the venous $\mathrm{CO}_{2}$ at discharge, were not significantly different between deceased and living participants. It is possible that $\mathrm{CO}_{2}$ levels may become a significant predictor of outcome as more patients are followed for longer periods of time. Other demographic factors, such as age, gender, and ethnicity, were not significant predictors of mortality. Age, however, may become a significant predictor of mortality after more patients are followed for a longer period of time. While patients older than the median age of 60 were significantly more likely to die $(p=0.02)$, there was not a significant difference in the age of participants who have died and those who are still alive.

\section{LIMITATIONS}

The process of data collection exposed difficulties in data collection. First, there were formidable difficulties in maintaining contact with these patients over time. Second, some participants reported difficulty or delays in receiving DME, leading to difficulty continuing DME following discharge. Third, the small study size is a limitation. We plan to correct this limitation by enrolling more patients and following them for a longer period of time. 


\section{Conclusions}

Patients hospitalized with chronic hypercapnic respiratory failure using NIV therapy had a significant, but lower than expected, one-year mortality rate of $16.7 \% \pm 0.71 \%$. Increased hours of NIV use per day was the only significant predictor of mortality, with increased hours of use being associated with greater mortality. Further study involving a larger cohort of patients with a longer time span is required to better understand which patients are at risk for death and how to avoid this outcome.

\section{FURTHER StUdIES}

Based on these results, we plan to follow patients out to 5 years to increase the cohort size and develop a more robust data set. Further action including checking $\mathrm{pCO}_{2}$ and venous $\mathrm{CO}_{2}$ of participants during follow up visits may allow us to specifically monitor physiologic changes associated with increased or decreased NIV use. This information may provide a better insight into the association between mortality and NIV use.

Article citation: Daines B, Mittal N, Ismail A, Berdine G. Survival following initiation of non-invasive ventilation during hospitalization for chronic hypercapnic respiratory failure. The Southwest Respiratory and Critical Care Chronicles 2021;9(37):40-44

From: Department of Internal Medicine, Texas Tech University Health Sciences Center, Lubbock, Texas

Submitted: 9/27/2020

Accepted: $12 / 1 / 2020$

Reviewer: Kenneth Nugent MD

Conflicts of interest: none

This work is licensed under a Creative Commons

Attribution-ShareAlike 4.0 International License.

\section{REFERENCES}

1. Connors AF Jr, Dawson NV, Thomas C, et al. SUPPORT Investigators (Study to Understand Prognoses and Preferences for Outcomes and Risks of Treatments). Outcomes following acute exacerbation of severe chronic obstructive lung disease. Am J Respir Crit Care Med 1996;154(4 pt 1):959-967.

2. Murray I, Paterson E, Thain G, et al. Outcomes following non-invasive ventilation for hypercapnic exacerbations of chronic obstructive pulmonary disease. Thorax 2011;66(9): 825-826.

3. Lindenauer PK, Dharmarajan K, Qin L, et al. Risk trajectories and death in the first year after hospitalization for chronic obstructive pulmonary disease. Am J Respir Crit Care Med 2017;197(8):1009-1017.

4. Budweiser S, Hitzl AP, Jorres RA, et al. Impact of noninvasive home ventilation on long term survival in chronic hypercapnic COPD: a prospective observational study. International J Clinical Practice 2007;61(9):1516-1522.

\section{Addendum: 4-8-2021}

The original article reported: "This study was approved (QIRB Approval \#19038) by Institutional Review Board at Texas Tech University Health Sciences Center, Lubbock, TX." This statement should be amended to read: "This study was approved (QIRB Approval \#19038) by the Quality Improvement Review Board at Texas Tech University Health Sciences Center, Lubbock, TX." 